ORIGINAL ARTICLE

\title{
PREVALENCE OF AMERICAN TRYPANOSOMIASIS AND LEISHMANIASES IN DOMESTIC DOGS IN A RURAL AREA OF THE MUNICIPALITY OF SÃO JOÃO DO PIAUIÍ, PIAUIÍSTATE, BRAZIL
}

\author{
Taliha Dias PEREZ(1), Fabiano Borges FIGUEIREDO(2), Artur Augusto Mendes VELHO JUNIOR(2), Valmir Laurentino SILVA(3),
} Maria de Fátima MADEIRA(4), Reginaldo Peçanha BRAZIL(1) \& José Rodrigues COURA(1)

\begin{abstract}
SUMMARY
Chagas disease and the leishmaniases are endemic zoonoses of great importance to public health in the state of Piauí, Brazil. The domestic dog (Canis familiaris) is a major reservoir, host of Trypanosoma cruzi and Leishmania spp. in both urban and rural areas, playing an important role in the transmission of these parasites. The present study evaluated the prevalence of both infectious diseases in dogs of a rural area in the municipality of São João do Piauí, Piauí State. One hundred twenty-nine blood samples were collected for serological assessment: for the leishmaniases, 49 (38\%) animals tested positive by the Dual-Path Platform technology (DPP), nine (6\%) by the Enzyme-linked Immunosorbent Assay (ELISA), and 19 (14.7\%) by the Indirect Fluorescent Antibody test (IFA); while for American Trypanosomiasis, 36 (28\%) dogs were reagent by ELISA and 21 by IFA. Of the 129 dogs sampled, 76 were submitted to xenodiagnosis, bone marrow aspiration and skin biopsy to perform parasitological tests whose results showed only one (2.3\%) positive skin sample for Trypanosoma caninum and one positive xenodiagnosis for T. cruzi, both results confirmed by molecular assays. Three hundred triatomines of the species Triatoma brasiliensis and 552 phlebotomines - 509 (97\%) of the species Lutzomyia longipalpis, were also captured.
\end{abstract}

KEYWORDS: Chaga's disease; Trypanosoma cruzi; Leishmaniases; Canine reservoir; São João do Piauí.

\section{INTRODUCTION}

Chagas disease (CD) as well as the leishmaniases are chronic, systemic diseases that are considered by the World Health Organization (WHO) and the Pan American Health Organization (PAHO) as neglected tropical diseases. The term 'neglected' highlights that these diseases affect poor and marginalized populations, especially in low-resource settings ${ }^{1}$.

American Trypanosomiasis (AT), also called Chagas disease, is a zoonosis produced by the flagellate protozoan Trypanosoma cruzi, and it is transmitted to humans by three different triatomine genera: Triatoma, Rhodnius or Panstrongylus, mainly by the vector through contact with infected feces ${ }^{2,3}$. Mammals are natural reservoirs of the parasite, and they play a key role in the maintenance and interaction of the domestic and sylvatic cycles of Chagas infection ${ }^{4,5}$. Persistence of parasitemia in dogs provides them with the opportunity to infect triatomines, then humans, and they have been used as efficient natural sentinels to assess T. cruzi reinfections ${ }^{6-8}$.

The leishmaniases are zoonoses that affect humans and other species of wild and domestic mammals with diverse clinical manifestations. They are caused by protozoa of the genus Leishmania, and their main form of transmission occurs through the bite of insect vectors of the Phlebotominae subfamily ${ }^{3,9,10}$. Dogs are admittedly the main reservoirs of Visceral Leishmaniasis (VL), with a strong positive association between areas of major concentration of human VL and places with high prevalence of seropositive animals ${ }^{11}$.

The World Health Organization (WHO) relies on two main stays for the control and elimination of Chagas disease: interruption of transmission and care to patients. Efforts to reduce transmission include mainly the interruption of intra-domiciliary vectorial transmission ${ }^{12}$ and the identification of domestic reservoir hosts. The main tools used by the Brazilian Visceral Leishmaniasis Control and Surveillance Program are canine surveillance measures that comprise the investigation of the focus, the active search for symptomatic dogs, and monitoring, which includes sample and census serological surveys ${ }^{13}$.

Both in Chagas disease and in the leishmaniases, the domestic dog is a risk factor for the population health, because it can be a source of

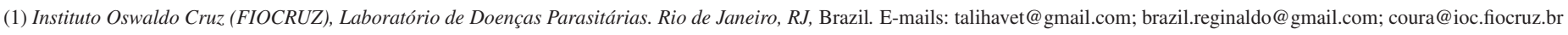

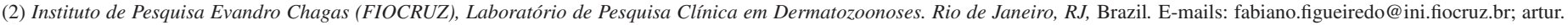
velho@ini.fiocruz.br

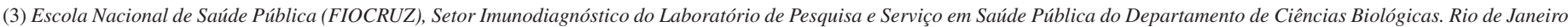
$R J$, Brazil. E-mail: valmir@ensp.fiocruz.br

(4) Instituto de Pesquisa Clínica Evandro Chagas (FIOCRUZ), Laboratório de Vigilância em Leishmanioses. Rio de Janeiro, RJ, Brazil. E-mail: fatima.madeira@ini.fiocruz.br

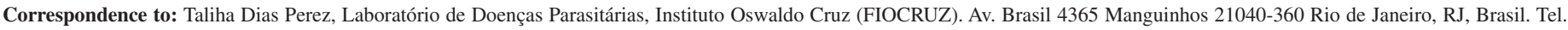
55.21.2562-1204; 55.21.99625-0054. E-mail: talihavet@gmail.com 
Perez TD, Figueiredo FB, Velho Junior AAM, Silva VL, Madeira MF, Brazil RP, Coura JR. Prevalence of American trypanosomiasis and leishmaniases in domestic dogs in a rural area of the municipality of São João do Piauí, Piauí State, Brazil. Rev Inst Med Trop Sao Paulo. 2016;58:79.

infection by T. cruzi and Leishmania spp. to humans, and the close contact between them, especially when dogs are kept indoors during the night, can significantly intensify the transmission of disease to human beings ${ }^{14}$. The interchanges among sylvatic, peridomestic and domestic cycles of the disease performed by these pets increase the contact with vector species and, consequently, the risk of vectorial infection or oral infection through the hunting and eating of wild animals ${ }^{14}$. Persistence of parasitemia in dogs provides them with the opportunity to infect triatomines, then humans, and they have been used as efficient natural sentinels to assess $T$. cruzi reinfections ${ }^{6-8}$.

Camargo et al. (1984) ${ }^{15}$ carried out the first study on Chagas infection with nationwide reach. This survey included data collected between 1975 and 1980, and indicated that the state of Piauí, among others, presented sparse entomological data and the record of a few cases of infection ${ }^{16}$.

Evidence of infection with Trypanossoma cruzi and Leishmania spp. in domestic dogs can be a good indicator of circulation and risk of human infection. The mere occurrence of triatomines and infected canine reservoirs in human dwellings hypothesizes the risk of transmission of Chagas disease and leishmaniases.

\section{MATERIAL AND METHODS}

\section{Study Area}

The municipality of São João do Piauí (SJPI) belongs to the $11^{\text {th }}$ Sanitary Region of Piauí State; it is located in the southeast region of the state, along the banks of the Piauí river, $450 \mathrm{~km}$ from the state capital Teresina. Its economy is concentrated in family farming and livestock and, more recently, in commerce; SJPI is one of the most important cities in the south of Piaui State (Fig. 1).

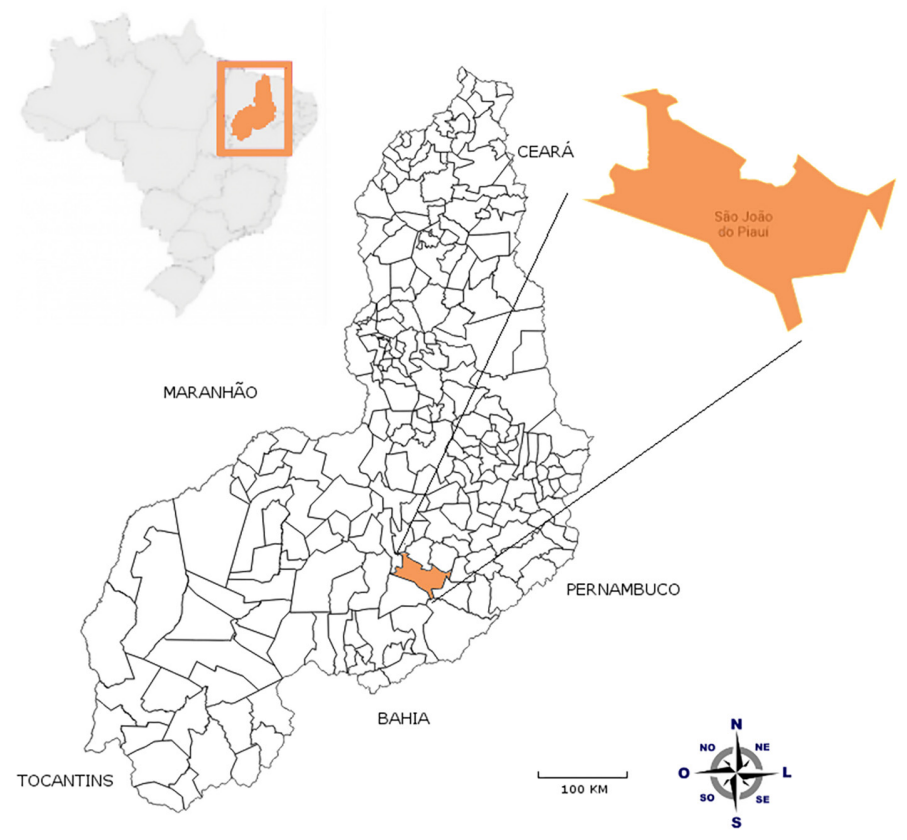

Fig. 1 - Map
Covering an area of $1,527,773 \mathrm{~km}^{2}$, the municipality of SJPI has a population of 19,553 inhabitants, with 6,083 residents living in rural $\operatorname{areas}^{17}$.

\section{Sampling}

A cross-sectional study was conducted on a convenience sample, through active search for dogs in the rural area of the municipality, between December 2013 and July 2014.

For this survey, dogs that lived in the area longer than six months, aged eight months or older, were included in the study after the informed consent of owners. Only blood sampling was performed in animals that did not present good general health or conditions to sedation, as well as in pregnant bitches, aggressive dogs and stray dogs. The procedures used in this animal study, were approved by the Ethics Committee on Animal Use (CEUA- FIOCRUZ), under the license number LW-43/10.

The dogs (76) were sedated with ketamine hydrochloride (10 mg/ $\mathrm{kg})$ associated with acepromazine maleate $(0.2 \mathrm{mg} / \mathrm{kg})$ and submitted to physical examination, blood collection, bone marrow aspiration and biopsy of intact skin fragments obtained from the scapular region. Xenodiagnosis was also conducted at this moment.

Dog blood samples (129) were collected by puncture of the cephalic vein, without anticoagulant, for the performance of serological tests.

For collection of skin fragments through biopsy (76), trichotomy was performed using disposable stainless steel blades, antisepsis and local anesthesia with $2 \%$ lidocaine without vasoconstrictor. Two intact skin fragments of the scapular region of each animal were collected using a 3-mm punch for parasitological tests. The fragments were stored in sterile physiological saline with antifungal and antibiotics for further processing in culture.

Bone marrow aspirates (76) were obtained from the sternum manubrium, using a $20 \mathrm{~mL}$ syringe with a $40 \times 12 \mathrm{~mm}$ needle, after trichotomy, antisepsis and local anesthesia with $2 \%$ lidocaine. Approximately $0.2 \mathrm{~mL}$ of the sample obtained in the aspirate was placed in a tube containing culture medium.

\section{Capture of insect vectors}

Three trained and experienced endemic surveillance agents conducted an active search for triatomines in the domiciliary and peridomiciliary areas of the participating residences between December 2013 and July 2014. The specimens captured were placed and transported in plastic vials with screw caps with small holes, containing filter paper cut and folded into an accordion shape. Each vial contained an identification label with the registration number of the residence, date, and place of collection (domiciliary or peridomiciliary area).

Collection of phlebotomines was conducted from June to July 2014, with CDC light traps, between $5 \mathrm{pm}$ and 6:00 am, totaling 27 hours of capture time. Each light trap was positioned 11/2 meter above the ground, and were installed in the three different ecotopes (domestic, peridomestic and sylvatic). Shannon type traps mounted approximately 20 to $30 \mathrm{~cm}$ off the ground were also used; a battery lantern was utilized to attract 


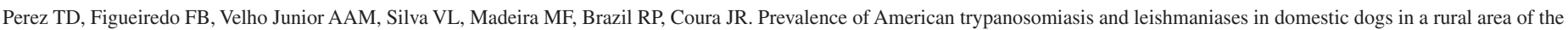
municipality of São João do Piauí, Piauí State, Brazil. Rev Inst Med Trop Sao Paulo. 2016;58:79.

the sandflies. The insects were captured by hand vacuum aspirators and stored in vials containing alcohol 70 GL.

\section{Serologic Assays}

The following tests were employed in the diagnosis of Visceral Leishmaniasis (VL): Indirect Fluorescent Antibody test (IFA), using L. (L.) chagasi promastigotes as antigens, following the methodology described by Camargo \& Rebonato (1969) ${ }^{12}$; Enzyme-linked Immunosorbent Assay (ELISA) and Dual-Path Platform technology (DPP ${ }^{\circledR}$ ), using commercial kits produced by BioManguinhos (FIOCRUZ; Rio de Janeiro, Brazil), distributed through the public health system.

The following tests were used in the diagnosis of American Trypanosomiasis (AT): Chagatest ELISA recombinant version 3.0 (Wiener lab.) with anti-human IgG antibody replaced with anti-dog IgG (Sigma-Aldrich); and an in-house IFA protocol standardized by the Immunodiagnostic Department of the Public Health Research and Service Laboratory (ENSP/FIOCRUZ) ${ }^{12}$.

\section{Parasitological test}

Twenty triatomine fourth-instar nymphs, ten nymphs of the Panstrongylus megistus species and ten of the Triatoma infestans species were used in the xenodiagnosis. These nymphs were placed in wooden boxes, with filter paper cut and folded into an accordion shape, covered with tulle, and fastened with rubber bands. Each box was labeled with the triatomine species, dog registration number, name and date.

Two boxes (one of each type) were placed on the abdomen of the animals for a 30-minute repast. After blood feeding, the nymphs that fed (which presented distended abdomen) were selected and placed in a new container. These nymphs received supplementary chicken blood (Gallus gallus) feeding, 15 days after the test, in order to maintain $T$. cruzi in the kissing bug.

When the xenodiagnosis was positive, the material was seeded in Novy-MacNeal-Nicolle (NNN) culture medium for isolation and identification by a molecular technique (Polymerase chain reaction (PCR) $)^{18}$

Parasite visualization was performed in the triatomines following the protocol of the Laboratory of Parasitic Diseases of Instituto Oswaldo Cruz - IOC, also based on the Training Manual on Trypanosoma cruzi Detection $^{19}$.

Identification of isolates of Trypanosoma caninum characteristic forms were categorized according to Pinto et al. $(2014)^{20}$.

Immediately after biopsy, the tissue samples (skin and skin lesions) were dipped in PBS solution, $\mathrm{pH} 7.4$, supplemented with antibiotics (penicillin and streptomycin) and antifungal (fluorocytosine), and kept at $4{ }^{\circ} \mathrm{C}$ for $24 \mathrm{~h}$. After this period, the samples were seeded in biphasic NNN culture medium containing Schneider medium supplemented with $10 \%$ fetal bovine serum as liquid phase. Approximately $0.2 \mathrm{~mL}$ of OM, obtained by puncture was seeded directly into the culture medium. The cultures were kept in organic greenhouse at $26-28^{\circ} \mathrm{C}$; they were examined weekly for 30 days by fresh examination in search for flagellate forms.

\section{RESULTS}

None of the animals investigated showed characteristic signs of Canine Visceral Leishmaniasis (CVL), such as hepatomegaly, splenomegaly, skin lesions, cachexia, apathy, onychogryphosis, local and generalized alopecia, edema of the limbs, or regional adenitis.

\section{Serology - Leishmaniasis}

One hundred twenty-nine (129) dog serum samples were analyzed: 49 of them (38\%) were positive by DPP, nine (6\%) by ELISA and 19 $(14.7 \%)$ by IFA (Table 1$)$.

Table 1

Results of the serological tests for Leishmania sp.

\begin{tabular}{lccc}
\hline Assays & Reagent & Non-reagent & Total \\
\hline DPP & $49(38 \%)$ & 80 & 129 \\
ELISA & $09(7 \%)$ & 120 & 129 \\
IFA & $19(14.7 \%)$ & 110 & 129 \\
DPP and ELISA & $09(7 \%)$ & 120 & 129 \\
ELISA and IFA & $06(4.6 \%)$ & 123 & 129 \\
DPP, ELISA and IFA & $06(4.6 \%)$ & 123 & 129 \\
\hline Total & $98(75.9 \%)$ & 676 & \\
\hline
\end{tabular}

Of the 129 samples, six (4\%) were positive in all serological tests performed for Leishmania sp. and nine (7\%) were positively concordant in the tests advocated by the Ministry of Health (MH) (DPP and ELISA).

\section{Serology - American trypanosomiasis}

One hundred twenty-nine (129) dogs were analyzed: 36 (28\%) were positive by ELISA and 21 (16.3\%) by IFA.

Of the 129 specimens analyzed, 10 (7.7\%) showed agreement in the two (2) tests (Table 2). Considering the condition of two positive serological results: DPP and ELISA for Leishmaniases, and ELISA and IFA for American trypanosomiasis, a co-positivity rate of $0.3 \%$ was observed, i.e, of the 15 animals with positive results for either one of the two conditions, only four were coincident for AT and VL.

Table 2

Results of the serological tests for T. cruzi

\begin{tabular}{lccc}
\hline Assays & Reagent & Non-reagent & Total \\
\hline ELISA & $36(28 \%)$ & 93 & 129 \\
IFA & $21(16.3 \%)$ & 108 & 129 \\
ELISA and IFA & $10(7.7 \%)$ & 119 & 129 \\
\hline Total & $67(53 \%)$ & 320 & \\
\hline
\end{tabular}

\section{Parasitological culture}

Only one $(2.3 \%)$ skin sample tested positive for the species Trypanosoma caninum. 


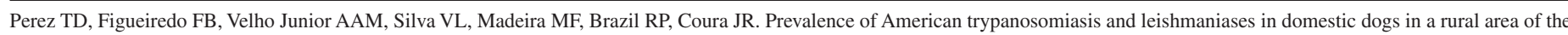
municipality of São João do Piauí, Piauí State, Brazil. Rev Inst Med Trop Sao Paulo. 2016;58:79.

In the xenodiagnosis, one (1.4\%) animal presented a positive parasitological result for $T$. cruzi, which was confirmed by $\mathrm{PCR}^{21}$. This animal also showed positive results in all the serological tests carried out for AT and VL.

\section{Taxonomic classification of the vectors}

All the triatomines captured (300) belonged to the species Triatoma brasiliensis. Five hundred twenty-two phlebotomines of the following species were captured: 509 (97.50\%) Lutzomyia longipalpis, one (0.2\%) L. migonei, seven $(1.34 \%)$ L. lenti and five $(0.96 \%)$ L. intermedia.

\section{DISCUSSION}

The epidemiological importance of the Brazilian northeast region for the maintenance and control of Chagas disease (CD) is well known, and it has been widely demonstrated in studies conducted in the region ${ }^{1,4,16,22}$. In 1984, Camargo et al. ${ }^{15}$ conducted the first survey on the prevalence of CD at national level between 1975 and 1980; in 2011, Silveira et al. ${ }^{22}$ detailed these results in their geographical distribution, where the Piauí State far surpassed the expected prevalence estimation in the country, being the sixth most prevalent State, with 4.04 seropositive individuals per one-hundred inhabitants.

Studies on the human seroprevalence of $T$. cruzi infection, specifically in the $11^{\text {th }}$ Sanitary Region of São João do Piauí, presented 216 seropositive results by IFA considering the 2,399 residents examined, a percentage of $5.3 \%$. When compared with the other Sanitary Regions studied, this percentage stands well above the average noted by the author ${ }^{16}$.

The municipality of SJPI is defined as an endemic area for CD, it presents an archaic basic structure for the control of this disease, and had only one case of human VL notified in 2014 (Communication of the Municipal Health Secretary). There are no studies providing information on LV either on the human population or on the canine population.

In view of the difficulties in controlling these diseases, the Brazilian Ministry of Health proposes an innovative methodology for surveillance and adopted preventive measures based on a better definition of areas of transmission or risk of transmission.

The new approach aims to incorporate the 'silent' states and municipalities, i.e., without human or canine cases of the disease, in the surveillance, thus aiming to avoid or minimize problems regarding aggravations in areas without transmission ${ }^{23}$.

The lack of characteristic signs and symptoms of AT and VL in the dogs investigated in this study is similar to the results presented by Santana et al.(2012) $)^{24}$, where naturally infected dogs in the northeastern semiarid region presented characteristics related to the undetermined chronic form, that is, asymptomatic dogs. This difficulty in the identification of naturally infected dogs, with no pathognomonic characteristics of CD and VL, complicates the diagnostic process and the prevention and control measures.

CD and VL are typical examples of organic injuries resulting from anthropic changes in the environment and of discrepant socioeconomic differences. The protozoa which are the causative agents of these diseases were restricted to sylvatic cycles, circulating among mammals and vectors in the natural environment ${ }^{25}$, and the promiscuity described in this study regarding the interaction between animal species in households and their owners are also factors that increase the risk of transmission of these diseases.

The high levels of prevalence of AT and VL, 77\% and 7\%, respectively, when the protocol of the Brazilian Ministry of Health that adopts two different serological techniques (ELISA and IFA for AT; DPP and ELISA for VL) for the laboratory diagnosis, exceed the values shown in previous studies ${ }^{16}$ for human CD serology.

Unfortunately, the lack of previous data on dogs in this region prevents us from making a comparison to assess whether there has been an increase or a decrease in the risk for the human population.

A study conducted by Mendes et al.(2013) ${ }^{26}$ with dogs naturally infected by Trypanosoma cruzi showed a prevalence of $4.08 \%$ in the rural area of the municipality of Patos, located in the semiarid region of the nearby Paraiba State, a significantly lower prevalence in comparison with that found in SJPI (7.7\%). The contextualization of the problem and the production of data on these diseases in the municipality of SJPI will bring a better understanding of epidemiological issues and pertinent entomological, political and administrative discussions.

In the present study, we were unable to demonstrate infection by Trypanossoma cruzi and Leishmania spp. in domestic dogs by parasitological cultures due to the high contamination rate $(60 \%)$ in this methodology, which can probably be explained by the very precarious laboratory structure of the municipality, as well as the long distance between sampling housing units.

However, the seropositivity of the tests performed to investigate the two diseases have confirmed, along with the high density of vectors, the high number of human cases in the region. Other authors ${ }^{27,28}$ have also reported dogs infected by $T$. cruzi in the southeast region of the USA and these cases have been associated with the domestic transmission of human infection. In 1978, Mott also demonstrated that seropositivity in human beings was five times higher in domiciles inhabited by infected dogs and cats than in those where there were no infected domestic animals ${ }^{29}$. In 2014, Curi et al. ${ }^{30}$ showed that dogs may be useful as sentinels for zoonotic leishmaniases in areas with uncertain epidemiological status.

Studies in areas of Atlantic forest fragments have presented some significant variables related to dog management and vector attractiveness (presence of other animals) as being negatively associated with seropositivity ${ }^{30}$. However, it was not possible to assess the exposure to risk factors in the dogs of this study because all of them were equally exposed to the same conditions, with access to the household, peridomicile and wild environment, and in close interaction with the other existing animals in the housing units.

The fact that one dog parasitized with Trypanosoma caninum was found, reinforces the importance of studies that search for these new species, and also investigate their epidemiology, as others authors have discussed $^{31}$. 
Perez TD, Figueiredo FB, Velho Junior AAM, Silva VL, Madeira MF, Brazil RP, Coura JR. Prevalence of American trypanosomiasis and leishmaniases in domestic dogs in a rural area of the municipality of São João do Piauí, Piauí State, Brazil. Rev Inst Med Trop Sao Paulo. 2016;58:79.

The Municipal Health Secretary of SJPI has no records of cases of canine leishmaniases in its database or notification $\log$, but the region is recognized as endemic for Chagas disease.

All of the dogs in the study area were exposed to the cycle of transmission of American trypanosomiasis and leishmaniases, a condition that is reinforced by the finding of positive dogs in all the housing units sampled. It is worth mentioning that $0.3 \%$ (four) of the animals were co-positive for T. cruzi and Leishmania spp., which configures a possible cross-reaction of the results obtained in the serological tests recommended by the Brazilian Ministry of Health for the diagnosis of both diseases. Nevertheless, even though we know that serological tests are not the most suitable for the confirmation of overlapping infections, the low co-positivity rate observed suggests a good specificity of the methods used.

In endemic areas for Chagas disease, such as the municipality of SJPI, as well as in other areas where there is an overlapping of the action of T. cruzi and Leishmania spp., routine diagnostic tests must always be evaluated with caution, possibly using more precise tools, such as molecular techniques.

\section{ACKNOWLEDGEMENTS}

The authors are grateful to the Municipal Secretary of São João do Piauí and its endemic surveillance agents for their support and participation, the Laboratory of Parasitic Diseases (IOC/Fiocruz) and Laboratory for Clinical Research on Dermatozoonoses in Domestic Animals (LAPCLIN-DERMZOO) (INI/FIOCRUZ), the Immunodiagnostic Department of the Public Health Research and Service Laboratory (ENSP/FIOCRUZ), namely Dr. Valmir Laurentino Filho, and to the entire team of the Leishmaniasis Surveillance Laboratory - VigiLeish INI/FIOCRUZ for their contribution to this study. The present study was financially supported by UNIVERSAL - MCTI/CNPq $N^{\circ} 14 / 2013$, Coordination for the Improvement of Higher Education Personnel - CAPES, and Rio de Janeiro Research Foundation (FAPERJ) - “Jovem Cientista do Nosso Estado” project. Fabiano Borges Figueiredo holds a grant from the Brazilian National Council for Scientific and Technological Development - CNPq for productivity in research.

\section{REFERENCES}

1. Pan American Health Organization. 10 vector-borne diseases that put the population of the Americas at risk. [cited 2014 Apr 5]. Available from: http://www.paho.org/hq/ index.php?option=com_content\&view=article\&id=9438\&Itemid=1926\&lang=en

2. Amato Neto V, Chieffi PP, Nisida IV, Umezawa ES, Sabino EC, Ruocco RM, et al Prevenção referente às modalidades alternativas de transmissão do Trypanosoma cruzi. Rev Med. 2000;79:12-26.

3. World Health Organization. Department of Control of Neglected Tropical Diseases. Sustaining the drive to overcome the global impact of neglected tropical diseases: second WHO report on neglected tropical diseases. Geneva: WHO; 2013.

4. Dias JC, Machado EM, Fernandes AL, Vinhaes MC. Esboço geral e perspectivas da doença de Chagas no Nordeste do Brasil. Cad Saude Publica. 2000;16 Supl 2:13-34.

5. Lauricella MA, Sinagra AJ, Paulone I, Riarte AR, Segura EL. Natural Trypanosoma cruzi infection in dogs of endemic areas of the Argentine Republic. Rev Inst Med Trop Sao Paulo. 1989;31:63-70
6. Castañera MB, Lauricella MA, Chuit R, Gürtler RE. Evaluation of dogs as sentinels of the transmission of Trypanosoma cruzi in a rural area of north-western Argentina. Ann Trop Med Parasitol. 1998;92:671-82.

7. Estrada-Franco JG, Bhatia V, Diaz-Albiter H, Ochoa-Garcia L, Barbabosa A, VazquezChagoyan JC, et al. Human Trypanosoma cruzi infection and seropositivity in dogs, Mexico. Emerg Infect Dis. 2006;12:624-30.

8. Gürtler RE, Cécere MC, Petersen RM, Rubel DN, Schweigmann NJ. Chagas disease in north-west Argentina: association between Trypanosoma cruzi parasitaemia in dogs and cats and infection rates in domestic Triatoma infestans. Trans R Soc Trop Med Hyg. 1993;87:12-5.

9. Deane LM, Deane MP. Visceral leishmaniasis in Brazil: geographical distribution and transmission. Rev Inst Med Trop Sao Paulo. 1962;4:198-212.

10. Marzochi MC, Marzochi KB. Tegumentary and visceral leishmaniases in Brazil emerging anthropozoonosis and possibilities for their control. Cad Saude Publica. 1994;10 Supl 2:359-75.

11. Oliveira CD, Assunção RM, Reis IA, Proietti FA. Spatial distribution of human and canine visceral leishmaniasis in Belo Horizonte, Minas Gerais State, Brasil, 1994 1997. Cad Saude Publica. 2001;17:1231-9.

12. Camargo ME, Rebonato C. Cross-reactivity in fluorescence tests for Trypanosoma and Leishmania antibodies. A simple inhibition procedure to ensure specific results. Am J Trop Med Hyg. 1969;18:500-5.

13. Brasil. Ministério da Saúde. Secretaria de Vigilância em Saúde. Departamento de Vigilância Epidemiológica. Doenças infecciosas e parasitárias: guia de bolso. $8^{\mathrm{a}} \mathrm{ed}$ rev. Brasília: Ministério da Saúde; 2010.

14. Coura JR, Dias JC. Epidemiology, control and surveillance of Chagas disease: 100 years after its discovery. Mem Inst Oswaldo Cruz. 2009;104 Supl 1:31-40.

15. Camargo ME, da Silva GR, de Castilho EA, Silveira AC. Inquérito sorológico da prevalência de infecção chagasica no Brasil, 1975/1980. Rev Inst Med Trop Sao Paulo. 1984;26:192-204.

16. Borges-Pereira J, de Castro JA, da Silva AG, Zauza PL, Bulhões TP, Gonçalves ME, et al. Soroprevalência da infecção chagásica no Estado do Piauí, 2002. Rev Soc Bras Med Trop. 2006;39:530-9.

17. Instituto Brasileiro de Geografia e Estatística. Censo Demográfico 2010: características gerais da população, religião e pessoas com deficiência. [cited 2014 Jan 1]. Available from: http://www.ibge.gov.br/home/estatistica/populacao/censo2010/default.shtm

18. Junqueira AC, Chiari E, Whicker P. Comparison of the polymerase chain reaction with two classical parasitological methods for the diagnosis of Chagas disease in an endemic region of north-eastern Brazil. Trans R Soc Trop Med Hyg. 1996;90:129-32.

19. Junqueira AC, Gonçalves TC. Curso de capacitação dos microscopistas de malária e dos laboratoristas da rede pública na detecção do Trypanosoma cruzi (módulos I, II e III). Rio de Janeiro: Instituto Oswaldo Cruz; 2014. [cited 2016 Jun 2]. Available from: http://brasil.campusvirtualsp.org/node/198026

20. Pinto AG, Toma HK, Figueiredo FB, Madeira MF. Evaluation of $18 \mathrm{~S}$ rDNA PCR assay using skin fragments as a diagnostic test for Trypanosoma caninum. Vet Parasitol. $2014 ; 205: 343-6$

21. Madeira MF, Sousa MA, Barros JH, Figueiredo FB, Fagundes A, Schubach A, et al. Trypanosoma caninum n. sp.(Protozoa: Kinetoplastida) isolated from intact skin of a domestic dog (Canis familiaris) captured in Rio de Janeiro, Brazil. Parasitology. 2009; 136:411-23

22. Silveira AC, Silva GR, Prata A. O inquérito de soroprevalência da infecção chagásica humana (1975-1980). Rev Soc Bras Med Trop. 2011;44 Supl 2:33-9. 
Perez TD, Figueiredo FB, Velho Junior AAM, Silva VL, Madeira MF, Brazil RP, Coura JR. Prevalence of American trypanosomiasis and leishmaniases in domestic dogs in a rural area of the municipality of São João do Piauí, Piauí State, Brazil. Rev Inst Med Trop Sao Paulo. 2016;58:79.

23. Ministério da Saúde. Secretaria de Vigilância em Saúde. Departamento de Vigilância Epidemiológica. Manual de vigilância e controle da leishmaniose visceral. Brasília: Ministério da Saúde; 2003.

24. Santana VL, Souza AP, Lima DA, Araújo AL, Justiniano SV, Dantas RP, et al. Caracterização clínica e laboratorial de cães naturalmente infectados com Trypanosoma cruzi no semiárido nordestino. Pesq Vet Bras. 2012;32:536-41.

25. Dias JC, Coura JR. Clínica e terapêutica da doença de Chagas: uma abordagem prática para o clínico geral. Rio de Janeiro: FIOCRUZ; 1997.

26. Mendes RS, Santana VL, Jansen AM, Xavier SC, Vidal IF, Rotondano TE, et al. Aspectos epidemiológicos da doença de Chagas canina no semiárido paraibano. Pesq Vet Bras. 2013;33:1459-65.

27. Duprey ZH, Steurer FJ, Rooney JA, Kirchhoff LV, Jackson JE, Rowton ED, et al. Canine visceral leishmaniasis, United States and Canada, 2000-2003. Emerg Infect Dis. 2006; $12: 440-6$
28. Kjos SA, Snowden KF, Craig TM, Lewis B, Ronald N, Olson JK. Distribution and characterization of canine Chagas disease in Texas. Vet Parasitol. 2008;152:249-56.

29. Mott KE, Mota EA, Sherlock I, Hoff R, Muniz TM, Oliveira TS, Draper CC. Trypanosoma cruzi infection in dogs and cats and household seroreactivity to T. cruzi in a rural community in northeast Brazil. Am J Trop Med Hyg. 1978;27:1123-7.

30. Curi NH, Paschoal AM, Massara RL, Marcelino AP, Ribeiro AA, Passamani M, et al. Factors associated with the seroprevalence of leishmaniasis in dogs living around Atlantic Forest fragments. PLoS One. 2014;9:e104003.

31. Barros JH, Almeida A, Figueiredo FB, Sousa VR, Fagundes A, Pinto AG, et al. Occurrence of Trypanosoma caninum in areas overlapping with leishmaniasis in Brazil: what is the real impact of canine leishmaniasis control? Trans R Soc Trop Med Hyg. 2012;106:419-23.

Received: 11 February 2015

Accepted: 02 June 2016 